\title{
PERAN KOMUNIKASI UNTUK MENINGKATKAN KINERJA PEMASARAN PERUMAHAN CAHAYA RESIDENCE PT. MILA CAHAYA HAKIJAYA DI BANJARMASIN
}

\author{
Milawati \\ Gusti Irhamni \\ Sanusi \\ E-mail: milawati@gmail.com

\begin{abstract}
Pascasarjana Magister Ilmu Komunikasi Universitas Islam Kalimantan MAB Banjarmasin
\end{abstract}

\begin{abstract}
This research explained role of advertising communication as one part of the business that must be managed well for internal interests and external interests of the company is marketing is by promoting property products through advertising media with the advantages perusahan the type of house in Cahaya Residence subsidized as an attraction for prospective customers who are implemented by PT. Mila Cahaya Hakijaya to increase sales.

The result of observation and discussion shows that the company implements the marketing process in several stages. Before implementing the marketing stage to the consumer, the marketing division of PT. Mila Cahaya Hakijaya conducts a market opportunity analysis and target market selection first to get a description on the market in the marketing process to be done. The pricing process of Cahaya Residence housing is highly considered by the company; it is because an appropriate price will benefit the company because the consumer's interest will increase so that it will be able to compete with other property company. In undertaking the marketing process of Cahaya Residence housing, PT. Mila Cahaya Hakijaya employed two marketing or promotion media, advertisement media and personal selling method. Advertisement media employed by the company included the billboard putting in the strategic place, brochure distribution, promotion via internet media and attending the property exhibition. Meanwhile the personal selling was carried out with face-to-face marketing method so that the consumer can receive clearly the message of advertisement delivered.
\end{abstract}

Keywords: Advertising Communication, performance, real estate 


\section{PENDAHULUAN}

Komunikasi pemasaran merupakan kunci keberhasilan usaha produsen. Hal ini membuat produsen wajib membina komunikasi dan hubungan dengan konsumennya supaya tidak lari ke produsen lainnya. Bisa dikatakan, komunikasi pemasaran merupakan bagian dari solusi bisnis dan bukan hanya solusi pemasaran belaka. Melalui manajemen yang baik serta teknik dan strategi pemasaran yang tepat komunikasi pemasaran dapat dijalankan.

Hal lain yang penting menjadi permasalahan perumahan dan pemukiman adalah keberadaan rumah subsidi yang diatur dalam Peraturan Pemerintah RI Nomor 64 Tahun 2016 mengenai Pembangunan Perumahan Masyarakat berpenghasilan rendah bahwa untuk percepatan penyediaan rumah bagi masyarakat berpenghasilan rendah berdasarkan Pasal 13 huruf g, Pasal 14 huruf i, Pasal 15 huruf n, dan Pasal 54 ayat (1) Undang-Undang Nomor 1 Tahun 2011 tentang Perumahan dan Kawasan Permukiman, perlu menetapkan Peraturan Pemerintah tentang Pembangunan Perumahan Masyarakat Berpenghasilan Rendah. Detail dari turuan ini juga diatur dalam.

Permen PUPR Nomor 425 /KPTS/M/2015 mengenai Batasan Harga Jual Rumah yang dapat diperoleh melalui kredit / pembiayaan kepemilikan rumah sejahtera, semakin mempermudah akses masyarakat untuk mendapatkan fasilitas perumahan dan pemukiman atau yang dikenal dengan perumahan bersubsidi.

Keadaan ekonomi daerah merupakan salah satu faktor yang mempengaruhi variasi jumlah unit terjual suatu produk rumah dalam kurun waktu tertentu di suatu daerah. Kebutuhan rumah sederhana sangat dibutuhkan oleh konsumen. Peluang usaha ini menjadi alasan pengembang perumahan PT. Mila Cahaya Hakijaya untuk juga meluncurkan 80 unit rumah sederhana dan bersubsidi untuk meringankan beban masyarakat kecil yang diberi nama perumahan Cahaya Residence. Dalam kurun waktu sampai 6 bulan produk rumah mereka sudah 50\% terjual, bahkan permintaan bertambah. Hal ini menjadikan pengembang menambah produk mereka sesuai dengan permintaan masyarakat. 
Pengembang telah melakukan berbagai cara untuk mempromosikan produk rumah, Pemasangan iklan di beberapa media cetak juga telah dilakukan untuk memenuhi target penjualan. Berbagai cara dilakukan untuk pemasaran properti yang dijalankan dalam penggarapan pangsa pasar efektif dan efisien, sehingga perlu diteliti mengenai "Peran Komunikasi Untuk Meningkatkan Kinerja Pemasaran Perumahan Cahaya Residence PT. Mila Cahaya Hakijaya"

Tujuan penelitian ini adalah untuk mengetahui dan menganalisis peran komunikasi pemasaran perumahan yang harus bagaimana dilakukan PT.Mila Cahaya Hakijaya untuk meningkatkan target pemasaran perumahan, untuk mengetahui faktor-faktor apa saja yang dapat mempengaruhi strategi pemasaran perumahan dalam meningkatkan kinerja pemasaran perumahan PT.MILA CAHAYA HAKIJAYA, dan cara yang akan diambil dalam keputusan mengatasi masalah / beban beban yang dihadapi dalam strategi pemasaran perumahan PT.Mila Cahaya Hakijaya.

\section{TINJAUAN PUSTAKA}

Komunikasi atau dalam bahasa inggris yaitu Communication pada dasarnya berasal dari bahasa Latin yaitu Communis yang berarti "sama", maksudnya adalah sama dalam arti kata dengan makna satu hal. Communico, communicatio atau communicare yang memiliki arti yaitu membuat sama atau make to common, secara signifikan komunikasi dapat terjadi jika ada kesamaan antara pengantar pesan dan penerima pesan atau antara komunikator dengan komunikan.

Komunikasi dapat dipahami sebagai penyampaian pesan, ide, atau informasi kepada orang lain dengan menggunakan saran tertentu guna mempengaruhi atau mengubah perilaku penerima pesan.

\section{Periklanan}

Periklanan adalah proses penyampaian informasi kepada konsumen dengan tujuan untuk mengajak konsumen untuk melakukan semuanya itu dengan melalui media. Periklanan atau advertising adalah salah satu media komunikasi massa yang berperan sangat penting dalam pemasaran atau marketing, politik, sosial, dan budaya. 
Sebagai salah satu komponen bauran komunikasi pemasaran atau bauran pemasaran atau marketing mix, periklanan biasanya digunakan produsen atau perusahaan untuk memberikan informasi tentang produk baru berupa barang atau jasa kepada masyarakat luas. Selain itu, periklanan juga ditujukan untuk menarik perhatian masyarakat, menciptakan kesadaran masyarakat tentang produk baru, dan mempengaruhi perilaku khalayak agar mau membeli produk yang ditawarkan.

Tujuan periklanan sendiri dapat dikelompokkan ke dalam dua kategori yaitu tujuan penjualan dan tujuan komunikasi. Adapun yang termasuk dalam tujuan komunikasi adalah membangun kesadaran atau memberikan informasi, menciptakan sikap yang diinginkan atau persuasi, dan merawat kesetiaan atau peneguhan.

\section{Strategi Pesan Periklanan}

Agar tujuan periklanan dapat tercapai maka pengiklan perlu merumuskan strategi pesan yang tepat. Sebuah iklan harus mampu menangkap atau menarik perhatian khalayak dengan cara memberikan informasi yang didukung dengan datadata atau dikemas melalui sebuah kisah serta disajikan dengan baik. Pesan iklan juga harus menarik minat khalayak dan ditafsirkan positif oleh khalayak.

Dalam psikologi komunikasi, pesan yang dirancang untuk menarik minat dan perhatian khalayak harus disusun secara terstruktur dan menggunakan beberapa imbauan pesan yang dapat menyentuh sisi kebutuhan dasar khalayak, kebutuhan sosial khalayak, dan kebutuhan psikologis khalayak. 


\section{ALUR KERANGKA FIKIR}

KONTRUKSI PESAN BROSUR :

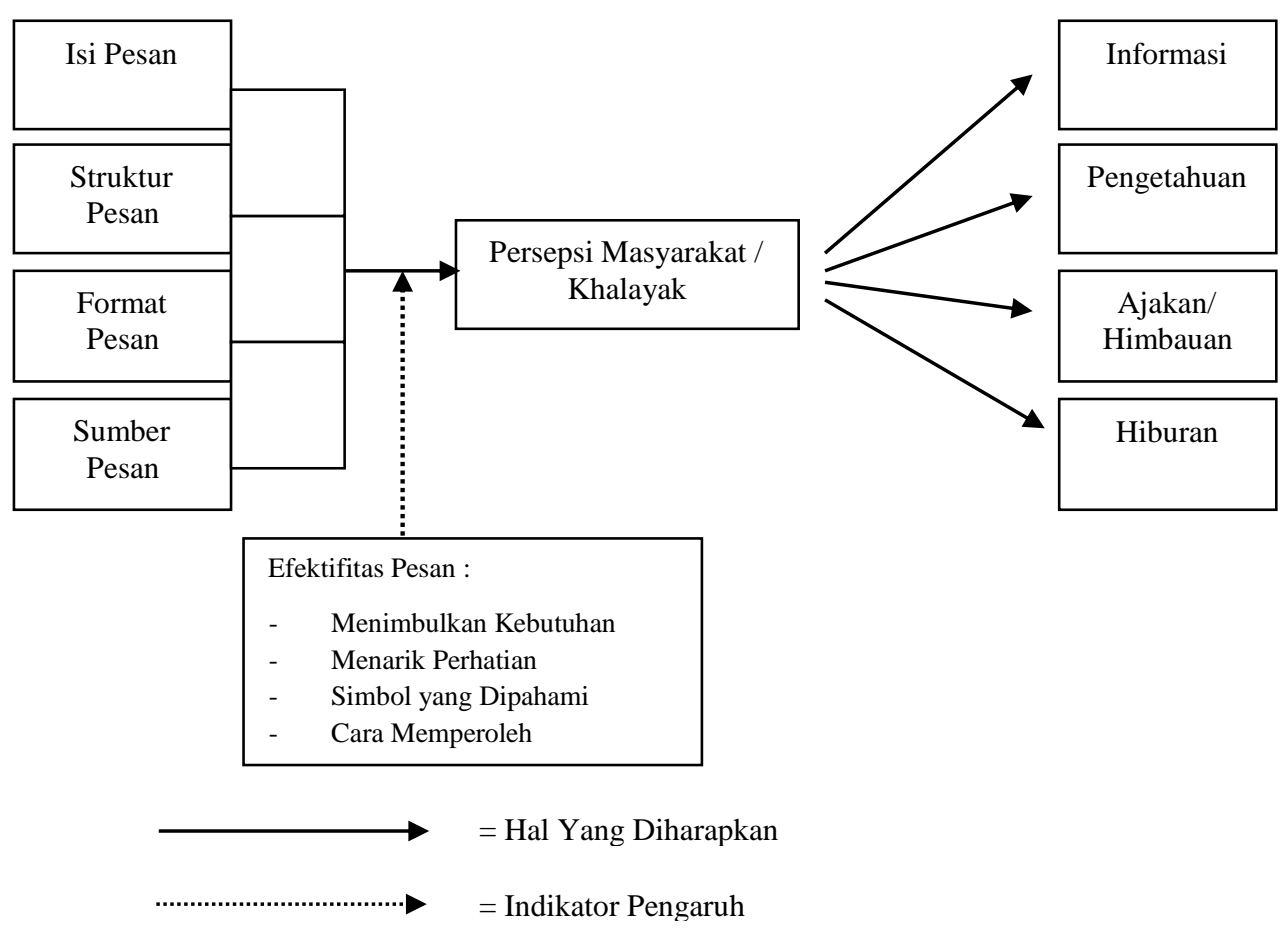

\section{Gambar 1 Alur Kerangka Fikir}

\section{Strategi Pemasaran}

Strategi pemasaran sebagai alat fundamental yang direncanakan untuk mencapai tujuan perusahaan dengan mengembangkan keunggulan bersaing yang berkesinambungan melalui pasar yang dimasuki dan program pemasaran yang digunakan untuk melayani pasar sasaran tersebut (Tjiptono, 2008:42-43).

Strategi pemasaran adalah bagian dari lingkungan yang terdiri atas rangsangan fisik dan sosial. Termasuk di dalam rangsangan tersebut adalah produk dan jasa, materi promosi (iklan), tempat pertukaran (toko eceran), dan informasi tentang harga (label yang tertempel pada produk), selanjutnya penerapan strategi pemasaran melibatkan penempatan rangsangan tersebut di lingkungan konsumen agar dapat mempengaruhi afeks, kognisi dan perilaku mereka (Peter J.P dan Olson J.C, 2008:43). 
Pada prinsipnya, strategi pemasaran memberikan arah dalam kaitannya dengan variabel-variabel seperti segmentasi pasar, identifikasi pasar sasaran, positioning, elemen bauran pemasaran dan biaya pemasaran, dimana strategi pemasaran merupakan bagian integral dari strategi bisnis yang memberikan arah bagi semua fungsi manajemen suatu organisasi (Tjiptono, 2008:43).

Dalam bisnis jasa pemasaran bersifat sangat kompleks karena banyak elemen yang mempengaruhi seperti internal organisasi, lingkungan fisik, komentar dari mulut-mulut, dsb. Oleh karena itu menurut Gronrous (dalam Philip Kotler 1994:469), mengemukakan bahwa pemasaran jasa ada 3 yaitu:

\section{a. Pemasaran Eksternal}

Dilakukan untuk menghubungkan perusahaan dengan nasabah perumahan, hal ini merupakan pekerjaan pemasaran yang dilakukan oleh perusahaan untuk menyiapkan, menentukan harga, mendistribusikan danmempromosikan jasa kepada nasabah perumahan.

b. Pemasaran Internal

Dilakukan untuk menghubungkan perusahaan dan karyawan, dalam hal ini perusahaan melatih dan memotivasi karyawan untuk melayani nasabah perumahan dengan baik.

c. Pemasaran Interaktif.

Dalam hal ini menghubungkan antara konsumen dengan karyawan dengan karyawan perusahaan. Pemasaran interaktif merupakan gambaran atas keahlian karyawan dalam melayani nasabah perumahan.

\section{METODE PENELITIAN}

Jenis penelitian yang digunakan penulis adalah metode penelitian deskriptif kualitatif yaitu penelitian yang berpola menggambarkan apa yang Ada dilapangan dan mengupayakan penggambaran data (Sudjarwo,2001:51). Sumber data utama berasal dari data primer dan sekunder. Teknik Pengumpulan Data dengan : Interview atau wawancara, observasi,dan dokumentasi. 
Wawancara

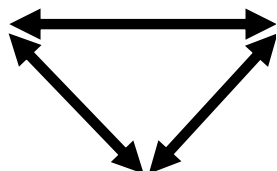

Kuisioner/Dokumen
Observasi

Aktivitas marketing yang dilakukan

Gambar 1 Triangulasi Teknik Pengumpulan Data

(Sumber : Modifikasi dari Sugiono, 2005: 126-127)

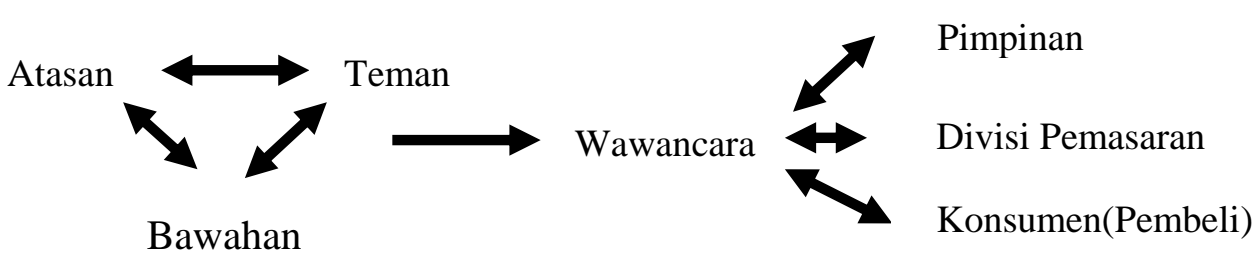

Gambar 2 Triangulasi Sumber

(Sumber : Modifikasi dari Sugiono, 2005: 126-127)

Teknik analisis data yang digunakan yaitu teknik analisis kualitatifyang dikembangkan oleh Milles danHuberman sebagaimana pada gambar 3 berikut :

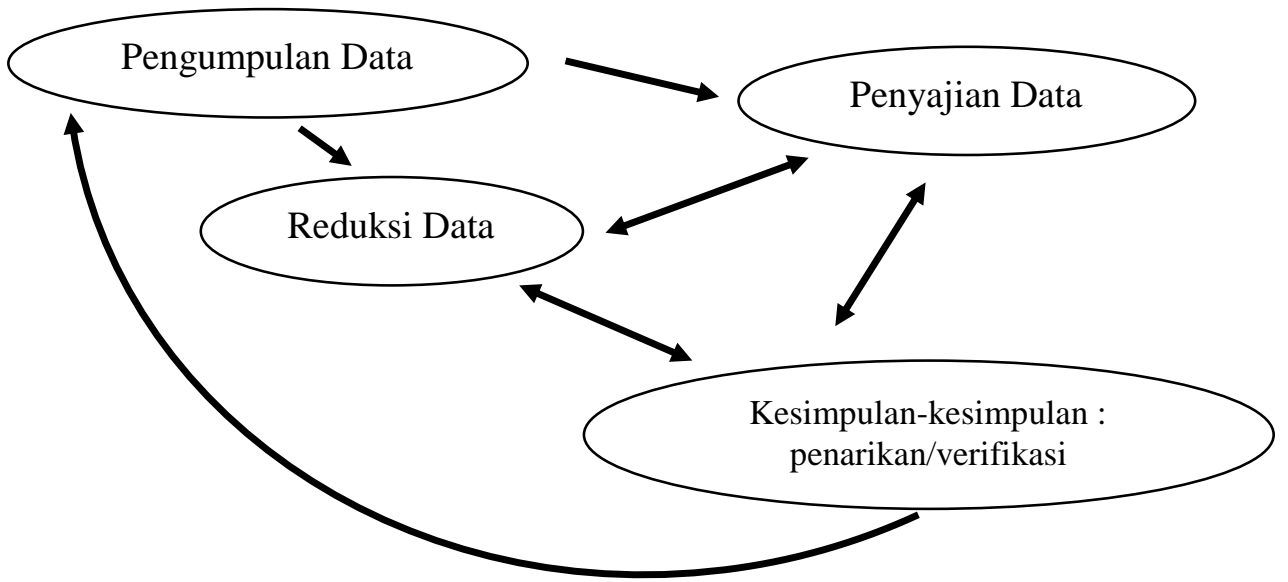

Gambar 3 Komponen-komponen Analisis DataModel Interaktif (Sumber: Miles, Huberman, 1992:20)

\section{HASIL PENELITIAN DAN PEMBAHASAN}

\section{Produk Dan Harga Perumahan}

Berdasarkan surat Permohonan Cek Peruntukan / informasi Ruang No.001/MCH/08/2017 tanggal 23 Agustus 2017,Oleh PT. Mila Cahaya Hakijaya kepada Dinas Pekerjaan Umum dan PenataanRuang Pemerintah Kota Banjarbaru disampaikan beberapa hal sebagai berikut : 
1.Analisis permohonan Informasi rencana pola ruang didasarkan pada :

a. Undang-undang Nomor 26 Tahun 2007 tentang Penataan Ruang.

b. Peraturan Pemerintah Nomor 15 Tahun 2010 tentang Penyelenggaraan Penataan Ruang.

c. Peraturan Daerah Kota Banjarbaru Nomor 13 Tahun 2014 tentang Rencana Tata Ruang Wilayah (RTRW) Kota Banjarbaru Tahun 2014-2034.

1. Permohonan tersebut diatas diajukan untuk pembangunan perumahan di kota Banjarbaru dengan data sebagai berikut :

Tabel 1. Rencana Tata ruang wilayah kota Banjarbaru

\begin{tabular}{|c|c|c|c|c|c|c|c|c|}
\hline No & Uraian & \multicolumn{7}{|c|}{ Informasi } \\
\hline 1 & Lokasi & \multicolumn{7}{|c|}{ Jalan Berkat Mufakat, Landasan Ulin Barat } \\
\hline 2 & Tujuan & \multicolumn{7}{|c|}{ Membangun Perumahan } \\
\hline 3 & Luas & \multicolumn{7}{|l|}{$19.888 \mathrm{M}^{2}$} \\
\hline \multirow{8}{*}{4} & \multirow{8}{*}{$\begin{array}{c}\text { Titik } \\
\text { Koordinat } \\
\text { Lokasi }\end{array}$} & No Titik & \multicolumn{3}{|c|}{ Bujur Timur } & \multicolumn{3}{|c|}{ Lintang Selatan } \\
\hline & & Koordinat & Derajat & Menit & Detik & Derajat & Menit & Detik \\
\hline & & 1 & 114 & 41 & 30,8 & 03 & 27 & 04,5 \\
\hline & & 2 & 114 & 41 & 35,3 & 03 & 27 & 05,1 \\
\hline & & 3 & 114 & 41 & 35,8 & 03 & 27 & 08,3 \\
\hline & & 4 & 114 & 41 & 33,6 & 03 & 27 & 08,8 \\
\hline & & 5 & 114 & 41 & 33,7 & 03 & 27 & 10,1 \\
\hline & & 6 & 114 & 41 & 31,7 & 03 & 27 & 10,5 \\
\hline
\end{tabular}

Sumber : Dinas PU dan Ruang Tata Kota Banjarbaru : 2017

2. Analisis terhadap rencana tata ruang wilayah (RT/RW) kota Banjarbaru berdasarkan pada peraturan daerah kota Banjarbaru nomor 13 tahun 2014 tentang rencana tata ruang wilayah (RT/RW) kota banjarbaru tahun 2014-2034 dapat disimpulakan sebagai berikut :

a. Analisis Pola Ruang

Berdasarkan pada hasil overlay terhadap titik koordinat yang diperoleh dari hasil survey lapangan disimpulkan bahwa lokasi yang dimaksud berada pada kawasan peruntukan Pemukiman dengan tingkat kepadatan sedang.

b. Analisis Ketentuan Umum.

1. Ketentuan umum kawasan peruntukan pemukiman adalah :

- Diperbolehkan membangun bangunan yang bersifat mendukung kegiatan perumahan (sarana pendidikan, sarana kesehatan, ruang 
terbuka hijau, taman dan lapangan olah raga) serta jaringan sarana dan prasarana wilayah pendukung fasilitas permukiman.

- Diperbolehkan secara bersyarat melakukan kegiatan industri skala rumah tangga dengan skala pelayanan lingkungan.

2. Ketentuan intensitas pemanfaatan ruang kawasan permukiman dengan kepadatan rendah :

- Kawasan perumahan dengan bentuk bangunan permanen.

- Luas kapling minimal $160 \mathrm{M}^{2}$

- Lebar jalan masuk minimal $10 \mathrm{M}$ dan jalan lingkungan minimal $8 \mathrm{M}$.

- Koefisien Dasar Bangunan (KDM) maksimal 60 \%

- Koefisien lantai bangunan (KLB) maksimal 1,2

- Garis sempadan bangunan (GSM) terhadap jalan lingkungan minimal $10 \mathrm{M}$

- Ketinggian bangunan maksimal 3 lantau.

Koefisien dasar hijau (KDH) minimum $30 \%$

Batasan harga jual rumah sejahtera tapak paling tinggi untuk tahun 20162018 dan batasan harga jual satuan rumah sejahtera susun paling tinggi yaitu :

Tabel 2 Batasan harga jual rumah tahun 2016-2018

\begin{tabular}{|c|l|c|c|c|}
\hline No. & \multicolumn{1}{|c|}{ Wilayah } & \multicolumn{1}{|c|}{$\begin{array}{c}2016 \\
\text { (Rp) }\end{array}$} & $\begin{array}{c}2017 \\
\text { (Rp) }\end{array}$ & $\begin{array}{c}2018 \\
\text { (Rp) }\end{array}$ \\
\hline 1. & $\begin{array}{l}\text { Jawa (kecuali Jakarta, } \\
\text { Bogor, Depok, Tangerang, } \\
\text { dan Bekasi) }\end{array}$ & 116.500 .000 & 123.000 .000 & 130.000 .000 \\
\hline 2. & $\begin{array}{l}\text { Sumatera (kecuali Kep. Riau } \\
\text { dan Bangka Belitung) }\end{array}$ & 116.500 .000 & 123.000 .000 & 130.000 .000 \\
\hline 3. & Kalimantan & 128.000 .000 & 135.000 .000 & 142.000 .000 \\
\hline 4. & Sulawesi & 122.500 .000 & 129.000 .000 & 136.000 .000 \\
\hline 5. & Maluku dan Maluku Utara & 133.500 .000 & 141.000 .000 & 148.500 .000 \\
\hline 6. & Bali dan Nusa Tenggara & 133.500 .000 & 141.000 .000 & 148.500 .000 \\
\hline 7. & Papua dan Papua Barat & 183.500 .000 & 193.500 .000 & 205.000 .000 \\
\hline 8. & $\begin{array}{l}\text { Kep. Riau dan Bangka } \\
\text { Belitung }\end{array}$ & 122.500 .000 & 129.000 .000 & 136.000 .000 \\
\hline 9. & $\begin{array}{l}\text { Jabodetabek (Jakarta, } \\
\text { Bogor, Depok, Tangerang, } \\
\text { dan Bekasi) }\end{array}$ & 133.500 .000 & 141.000 .000 & 148.500 .000 \\
\hline
\end{tabular}

Sumber : Keputusan Menteri Pekerjaan Umum dan Perumahan Rakyat Nomor 425/KPTS//M/2015 
Adapun perumahan Subsidi Tipe 36/160M² yang akan dibangun sebanyak 80 unit, telah terjual sebanyak 80 unit rumah.

Tabel 3 Daftar Produk, Harga dan Angsuran Perumahan "Cahaya Residence"

\begin{tabular}{|c|c|c|c|c|c|c|c|}
\hline \multirow{2}{*}{ TYPE } & \multirow{2}{*}{ HARGA } & \multirow{2}{*}{ DP } & \multirow{2}{*}{ KPR } & \multicolumn{4}{|c|}{ CICILAN BULANAN } \\
\cline { 5 - 8 } & & & & 5 th & 10th & 15th & 20th \\
\hline $36 / 160$ & 135.000 .000 & 7.000 .000 & 128.000 .000 & 2.416 .000 & 1.358 .000 & 1.013 .000 & 845.000 \\
\hline
\end{tabular}

Sumber : Data PT. Mila Cahaya Hakijaya 2017

\section{Peran komunikasi Periklanan untuk Meningkatkan Pemasaran}

Manajemen pemasaran melihat iklan sebagai bagian dari strategi promosi secara keseluruhan. Komponen lainnya dari promosi termasuk publisitas, hubungan masyarakat, penjualan, dan promosi penjualan. Iklan merupakan usaha komunikasi pemasaran yang dilakukan oleh organisasi atau perusahaan untuk memberikan informasi melalui berbagai media.

Tujuan periklanan yang terutama adalah menjual dan meningkatkan penjualan barang atau jasa, ide. Dari segi lain, tujuan periklanan yang riil adalah mengadakan komunikasi secara efektif. Masyarakat sebagai penerima berita atau iklan sering dapat terpengaruh dan ingin mengubah sikap atau tingkah laku konsumen. Tetapi masyarakat atau bahkan pengusaha sendiri tidak menyadari adanya kenyataan tersebut. Dengan demikian secara umum dapat dikatakan bahwa tujuan periklanan adalah untuk meningkatkan penjualan yang menguntungkan.

Perusahaan harus menetapkan tujuan terlebih dahulu sebelum membuat iklan, yang bertujuan agar iklan tersebut tepat sasaran dan menjadi iklan yang efektif. Tujuan iklan menurut Kotler dan Keller adalah sebagai berikut :

1. Memberikan informasi (iklan informatif). Iklan menciptakan kesadaran dan pengetahuan tentang produk baru atau ciri baru produk yang sudah ada di pasar.

2. Membujuk (iklan persuasif) Iklan menciptakan kesukaan, prefensi, membujuk, keyakinan, dan pembelian suatu produk atau jasa.. Hal ini sangat penting, terutama dalam tahap persaingan dimana perusahaan ingin membangun permintaan selektif untuk produk tertentu. 
3. Mengingatkan (iklan pengingat). Iklan menciptakan pengingat untuk konsumen pada produk atau merek perusahaan. Ketika timbul kebutuhan yang berkaitan dengan produk tertentu, konsumen akan mengingat iklan tentang produk tersebut. Jadi, iklan juga bertujuan untuk mengingatkan atau merangsang pembelian produk dan jasa kembali.

4. Menguatkan (iklan penguatan). Iklan menciptakan penguatan untuk konsumen yang sudah ada bahwa mereka telah melakukan pilihan yang benar dan tepat karena sudah membeli atau menggunakan produk.

\section{Strategi Komunikasi Periklanan.}

Beberapa cara yang telah dilakukan dalam proses pemasaran perumahan PT. Mila Cahaya Hakijaya adalah sebagai berikut :

1. Iklan dengan menggunakan media brosur / selebaran.

Alternatif media dengan menggunakan media brosur dan selebaran memiliki keunggulan dengan biaya yang relatif murah dan waktu edar cepat tetapi media ini juga kurang efektif apabila tidak diimbangi dengan media lain. Hal ini dikarenakan ruang iklan dengan menggunakan brosur dan selebaran terbatas serta kurang jelas informasi yang diperoleh konsumen.

2. Iklan dengan menggunakan media ruang publik.

Alternatif media dengan memanfaatkan media ruang publik adalah sebagai berikut :

a. Poster yang ditempel didepanpagar rumah, tiang listrik dan sebagainya.

b. Spanduk yang dipasang diluar kantor PT. Mila Cahaya Hakijaya dan daerah sekitar perumahan.

c. Baleho dan billboard.

Keuntungan menggunakan media ini adalah penampilannya yang menarik, sangat mudah dilihat orang banyak karena ukuran yang besar, dan pesan didalamnya dapat tertangkap jelas dalam pemikiran masyarakat luas. 
3. Bauran Komunikasi Pemasaran (Marketing Communication Mix).

PT.Mila Cahaya Hakijaya melakukan kegiatan periklanan, promosi penjualan, personal selling, pemasaran langsung serta publisitas dan hubungan masyarakat untuk memasarkan perumahan kepada konsumen.

4. Segmentasi Pasar.

Agar proses pemasaran dapat berjalan dengan tepat diperlukan adanya pemilihan pasar sasaran. Pasar sasaran sendiri adalah bagian pasar yang dijadikan sebagai tujuan pemasaran. Segmentasi pasar merupakan salah satu strategi yang sangat penting dalam mengembangkan program pemasaran perumahan PT. Mila Cahaya Hakijaya. Dengan melakukan segmentasi pasar diharapkan usaha-usaha pemasaran yang dilakukan PT. Mila Cahaya Hakijaya dapat mencapai tujuan secara efektif dan efisien. Disampaikan melalui berbagai bentuk komunikasi pemasaran mendapatkan tanggapan yang baik dari masyarakat. Dalam hal ini, perusahaan harus peka terhadap respon public setelah proses penyampaian pesan dilakukan. Kepekaan yang dimiliki oleh PT.MILA CAHAYA HAKIJAYA diwujudkan melalui pelayanan terhadap konsumen dari sebelum melakukan pembelian, saat pembelian dan setelah pembelian. Hal ini sejalan dengan teori Rhetorical Sensitivity yang dikembangkan oleh Roderick Hartz. Rhetorical Sensitivity adalah komunikator Yang moderat, yang peduli terhadap dirinya,orang lain dan kondisi situasional.

PT.MILA CAHAYA HAKIJAYA memiliki kepedulian terhadap kondisi dan situasi calon konsumen maupun konsumen. Kepedulian terhadap calon konsumen diwujudkan dengan mempermudah calon konsumen melakukan transaksi pembelian rumah. Bagi konsumen, kepedulian diwujudkan dengan memperhatikan dan mengatasi keluhan-keluhan yang berkaitan dengan perumahan yang dialami konsumen. Hal ini juga merupakan suatu wujud dari pelayanan purna jual yang diterapkan oleh PT.MILA CAHAYA HAKIJAYA 


\section{Masalah dan solusi Pemasaran Perumahan PT. Mila Cahaya Hakijaya}

Masalah yang dapat timbul pada iklan pemasaran diantaranya :

1. Strategi apa yang harus diambil dalam media iklan untuk memasarkan 80 unit rumah subsidi yang harus terjual sesuai target yang sudah di tetapkan.

2. Bagaimana cara meningkatkan mutu bangunan perumahan yang berkualitas di atas standar untuk menarik minat nasabah.

\section{Solusi dalam pemasaran Perumahan PT. Mila Cahaya Hakijaya}

1. Merubah tampilan pada brosur iklan dalam periode tertentu dengan memberikan bonus tambahan berupa carport, TV, AC, Pagar, dan Taman (pilih salah satu).

2. Pengerjaan rumah langsung dikerjakan oleh perusahaan langsung bukan kerja sama dengan kontraktor/sub kontraktor.

3. Undian 1 unit Motor Matik Beat Pop untuk 10 Nasabah pertama, kedua, ketiga dan ke empat (4 kali pengundian hadiah).

4. Tanda Jadi Nol persen (0\%) langsung DP unit rumah Rp.7.000.000,- bisa di cicil selama 3 bulan.

5. Memberi Fee tambahan untuk Tim Pemasaran (Sales pemasaran, Nasabah dan Relasi) yang ketentuannya Rp. 1.000.000,-/unit menjadi Rp. 1.500.000,-/unit.

Dari laporan bulanan bagian Marketing produksi pembangunan rumah di dapatkan informasi pada bulan Mei 2018 bahwa 80 unit rumah subsidi sudah habis terjual.

DP 80 nasabah perumahan Cahaya Residence sudah masuk dan berkas persyaratan KPR nasabah sudah mulai dilengkapi oleh nasabah.

Bila semua berkas nasabah sudah lengkap maka kewajiban pengembang menyerahkan ke bank yang sudah kontrak kerjasama, salah satu Bank yang kontrak kerjasama dengan PT. MILA CAHAYA HAKIJAYA adalah BTN Syariah.

Proses selanjutnya Tim Survey BTN Syariah akan menyurvey tempat kerja bagi PNS dan Karyawan Swasta atau tempat Usaha / toko bagi nasabah wiraswasta. 
Kemudian Karyawan BTN Syariah akan menghubungi pengembang dan nasabah lewat telpon untuk memberikan informasi jadwal wawancara KPR perumahan.

Tidak berapa lama menunggu nasabah akan Akad KPR dengan BTN Syariah dengan catatan bahwa rumah nasabah yang akan di Akad sudah selesai 100\% dibangunkan dan sudah dapat fasilitas PLN dan PDAM.

Sesudah proses Akad KPR nasabah di BTN Syariah terlaksana maka BTN Syariah akan membayar harga rumah subsidi kepada pengembang, maka cash follow perusahaan akan masuk dan bertambah sampai selesai Akad KPR 80 unit rumah subsidi.

\section{KESIMPULAN}

1. Peran komunikasi pemasaran perumahan yang di lakukan sekarang oleh PT. Mila Cahaya Hakijaya yaitu cara menyampaikan pesan penawaran mengenai informasi tentang perumahan, membujuk agar konsumen yakin dan mengingatkan tentang iklan perumahan tersebut sampai rumah tersebut laku terjual. Hal ini membuat perusahaan wajib membina komunikasi dan hubungan dengan konsumennya supaya tidak lari ke perusahaan lainnya.

2. Strategi untuk meningkatkan kinerja pemasaran perumahan oleh PT.Mila Cahaya Hakijaya yaitu melalui media iklan dengan menggunakan media brosur, media ruang publik, media internet,dan pameran perumahan, serta sasaran pemasarannya menggunakan metode personal selling untuk lembaga-lembaga atau instansi pemerintah maupun swasta yang berada di wilayah tersebut.

3. Cara mengatasi masalah yang dihadapi dalam strategi pemasaran perumahan oleh PT.Mila Cahaya Hakijaya yaitu harus menghabiskan 80 unit rumah subsidi yang sudah ditargetkan dengan cara merubah tampilan pada brosur iklan dalam periode tertentu dengan memberikan mutu bangunan yang berkualitas standar dan bonus tambahan berupa carport,TV,AC,Pagar, dan Taman, serta ada undian 1 buah unit motor untuk 10 pendaftar pertama dengan 4 kali pengundian, pengerjaan rumah juga langsung dikerjakan oleh perusahaan bukan kerja sama 
dengan kontraktor/sub kontraktor, tanda jadi nol persen ( $0 \%)$ langsung DP bisa dicicil selama 3 bulan, serta meningkatkan fee tambahan untuk sales pemasaran yang sudah berhasil menjual rumah tersebut.

\section{DAFTAR PUSTAKA}

Abrams, 1664. Karakteristik Masyarakat yang Tinggal di Perumahan.

Anna Yulia Wulandari, 2015. Analisis kompetensi komunikasi customer service dalam meningkatkan kepuasan pelayanan public(Studi pada badan pelayanan perijinan terpadu dan penanaman modal kota banjarbaru)

Budihardjo, Eko, 1998. Sejumlah Masalah Pemukiman Kota. Bandung : Alumni.

Budi Lesmana, 2011. Pengaruh media komunikasi luar ruang (baliho) pemerintah daerah hulu sungai utara terhadap prestasi masyarakat kota amuntai.

Cangara, Hafield. Prof. Dr. 2010. Pengantar ilmu komunikasi-Edisi Revisi. Rajawali press Jakarta.

Chandra,Gregorius, 2002, Strategi dan ProgramPemasaran, PenerbitANDI, Yogyakarta

Effendi, Onong, 2003, Ilmu, Teori dan FilsafatKomunikasi, PT. Citra Aditya Bakti,Bandung.

Frendy Arsanda Kisida Putra, 2011. Pemasaran property pada PT. Tri Maesa Buwana Karang Anyar. http://eprints.uns.ac.id/7149/1/213801511201102131.pdf. Jam $12: 30$ WITA.

Hal yang harus terdapat dalam brosur - Graphic Design Agency Indonesiahttp://www.soocadesign.com/. Jam 21.15 WITA.

Kasali, Rhenald, 2007, Manajemen Periklanan:Konsep dan Aplikasinya di Indonesia,PT. PustakaUtama Grafiti, Jakarta.

Kajian Strategi Komunikasi Pemasaran Rumah Panggung di Woloan oleh Enggelina Onna Jeklin Supit - https://media.neliti.com>publications. Jam 12.22 WITA.

Komunikasi Pemasaran Sebagai Strategi Memperluas Pasar - 04-29-2014 Universitas Esa Unggul - http://www.esaunggul.ac.idl. Jam 20.35 WITA.

Kotler, Philip, 1988, Manajemen Pemasaran:Analisis, Perencanaan dan Pengendalian.Penerbit ERLANGGA, Jakarta.

Littlejohn, StephenW, 1995, Theories of HumanCommunication,Wadsworth PublishingCompany, London.

M. Suyanto, Marketing Strategy Top Brand Indonesia, Andi Yogyakart

Macam-macam media iklan untuk promosi http://web.bisnis.com/macam-macam-iklanuntuk-promos/amp/. Jam 12:46 WITA.

Moelong, Lexy, 2007, Metode PenelitianKualitatif, PT. Remaja Rosdaskarya,Bandung.

Muhammad Arsyad, 2011. Srategi pemasaran pariwisata melalui media dan kalender event pada dinas pemuda, olahraga, kebudayaan dan pariwisata Kalimantan selatan. 
Musthofa, Bisri, 2008. Kamus Kependudukan . Yogyakarta : Panji Pustaka

17 Peran Komunikasi Pemasaran Secara Umum. https://pakarkomunikasicom.cdn.ampproject.org. Jam 11.46 WITA.

Peran Iklan Dalam Pemasaran Produk Dan Jasa Perusahaan/Barra Indonesia Project. http://www.barraproject.co.id>peran-iklan-dalam-pemasaran-produk-dan-jasaperusahaanl. Jam 20.25 WITA.

Peranan komunikasi pemasaran Dalam meningkatkan minat pengguna iklan Di harian komentar manado,2014. https://media.neliti.com>publications/. Jam 14.19 WITA.

Peranan Periklanan http://sitijuwa.blogspot.co.idl. jam 19.53 wita.

Prisgunanto, Ilham, 2006, Komunikasi Pemasaran:Strategi dan Taktik, Ghalia Indonesia,Bogor.

Rakhmat, Jallaludin, 1991, Metode PenelitianKomunikasi, Remaja Rosda Karya,Bandung.

Ruslan, Rosady, 2004, Metode PenelitianPublic Relations dan Komunikasi, RajaGrafindo Persada, Jakarta.

Shimp, TerenceA, 2003, Periklanan Promosi: Aspek Tambahan Komunikasi PemasaranTerpadu, Penerbit ERLANGGA,Jakarta

Sudjarwo, 2001, Metode Penelitian Sosial,PenerbitMandarMaju, Bandung.

Sugiyono, 2005, Memahami PenelitianKualitatif, PenerbitAlfabeta, Bandung.

Strategi, Isi Pesan dan Visualisasi dalam Komunikasi Promosi \& Pemasaran https://qoechil.wordpress.com. Jam 21.18 WITA.

Wiryanto, 2004. Pengantar ilmu komunikasi, PT. Gramedia Jakarta

Yudhohusodo, Siswanto, dkk. 1991, Rumah untuk Seluruh Rakyat, INKOPPOL, Jakarta. 